\title{
LAS MUJERES DE LA REPÚBLICA Y LA GUERRA CIVIL DESDE LA PERSPECTIVA DEMOCRÁTICA ACTUAL $^{1}$
}

\author{
Mónica Moreno Seco
}

\section{MEMORIA E HISTORIA DE LAS MUJERES REPUBLICANAS}

Las relaciones entre memoria e historia se han convertido en un elemento central del interés historiográfico y filosófico de nuestro tiempo. En España, el debate se centra en la destacada atención social y la investigación historiográfica sobre la República, la Guerra Civil y el Franquismo, por la mitificación o el rechazo de personajes y procesos, frente a un análisis historiográfico dominado por los grises y los matices. A pesar de la intensidad de la controversia, no se suele aludir a las experiencias femeninas de los años treinta, que también son recordadas de forma sesgada y contribuyen a mitificar el pasado. Con una apariencia despolitizada, las vivencias de mujeres anónimas («inocentes») resultan especialmente atractivas para el gran público, lo cual explica la proliferación de publicaciones periodísticas y documentales sobre esta cuestión. La pervivencia de mitos y de enfoques abandonados por la historia académica conduce a preguntarse si la investigación historiográfica responde a la demanda de saber de la sociedad actual ${ }^{2}$. Sánchez León responde con crudeza: «el relato producido por los historiadores, un relato impersonal y con una falsa equidistancia, se ha ido mostrando incapaz con el tiempo de satisfacer los cambios en la sensibilidad del público", que reclama "una historia con sujeto». Precisamente este autor menciona la historia de las mujeres como el ámbito académico que más se aproxima

1. Este trabajo se enmarca en el proyecto de investigación "Del consenso constitucional al enfrentamiento partidista en España, 1977-2004", financiado por el Ministerio de Ciencia y Tecnología (HUM2005-03816).

2. ARÓstegui, Julio y Godicheau, François, «Presentación» a ARÓsteguI, Julio y GodicheaU, François (eds), Guerra Civil. Mito y memoria, Madrid, 2006, p. 19. 
a la demanda de recuperar lo subjetivo ${ }^{3}$. Tanto el destacado interés social que las mujeres de la República y la Guerra despiertan, como la existencia de una nutrida y sólida historiografía de género justifican, a nuestro entender, que la memoria de las mujeres ocupe un lugar en este debate.

En el presente texto no se ofrece un análisis de la situación de las mujeres que vivieron en la etapa republicana y en el bando democrático durante el conflicto, sino unas reflexiones sobre la impronta de su memoria en la actualidad. Nos interesa destacar qué se recuerda, qué valores se asocian a esa memoria y qué mecanismos de socialización han conducido a ello ${ }^{4}$. Tanto la República como la Guerra son etapas del pasado que forman parte de la memoria social española, que influyen en el presente de forma positiva o negativa: en la actualidad, la República se presenta como modelo democrático y la Guerra como contramodelo a evitar ${ }^{5}$, si bien en el caso de las mujeres es percibido también como un tiempo heroico. La memoria, en opinión de Aróstegui, es una referencia decisiva en procesos de identidad, además de suministradora de pautas para la acción ${ }^{6}$. En este sentido, el recuerdo recurrente de mujeres víctimas o de heroínas individuales en los años treinta remite a una participación limitada de las mujeres en el ámbito público y en la política. No obstante, el panorama es complejo, por la convivencia y entrecruzamiento de diferentes memorias en un momento dado ${ }^{7}$, como sucede en nuestros días. Como indica Josefina Cuesta, existen distintos tipos de memoria, entre ellos, la memoria social-amplia, con contornos difusos- y la memoria colectiva, de un grupo más reducido ${ }^{8}$ : en nuestro caso, puede hablarse de una memoria social despolitizada, y de una memoria colectiva de grupos de izquierda, más ideologizada pero también mitificadora, como se puso de manifiesto en 2006 con motivo de los numerosos actos de conmemoración del $75^{\circ}$ aniversario de la proclamación de la República y del $70^{\circ}$ aniversario del comienzo de la Guerra.

Pérez Garzón propone reescribir la historia incorporando memorias subordinadas y silenciadas, entre ellas, las femeninas ${ }^{9}$. En el mismo sentido, Monserrat Duch insiste en la ausencia y el olvido de mujeres en la memoria actual de la sociedad española y considera necesario rehabilitar las memorias femeninas ${ }^{10}$. Sin embargo, estando de acuerdo en términos generales con lo anterior, para las mujeres de la República y la Guerra, precisamente las más (o las únicas) cono-

3. SÁNCHEZ LEÓN, Pablo, «La objetividad como ortodoxia: los historiadores y el conocimiento de la guerra civil española», en ARÓsTEGUI, Julio y GODICHEAU, François (eds.), op. cit., pp. 130-131.

4. Planteamiento que tomo del que hace Paloma AGUILAR FERNÁNDEZ para la Guerra, en Memoria y olvido de la Guerra Civil española, Madrid, 1996, p. 56.

5. Ibidem, pp. 35-36.

6. ARÓstegui, Julio, La historia vivida. Sobre la historia del presente, Madrid, 2004, pp. 156 y 160.

7. CUeSTA, Josefina, "Memoria e historia. Un estado de la cuestión», Ayer, nº 32 (1998), p. 211.

8. Cuesta, Josefina, Historia del presente, Madrid, 1993, pp. 42-45.

9. PÉreZ GARZÓN, Juan Sisinio, «Los historiadores en la política española», en CARRERAS ARES, Juan José y ForCadell ÁlVAREZ, Carlos (eds.), Usos públicos de la Historia, Madrid, 2003, p. 142.

10. DuCH Plana, Montserrat, Dones públiques. Política i gènere a l'Espanya del segle XX, Tarragona, 2005, pp. 21-22. 
cidas de la historia de nuestro país, puede ser interesante estudiar qué y cómo se recuerda y qué se olvida sobre ellas en la memoria actual española. Y la influencia que tiene esta memoria selectiva en la percepción del funcionamiento democrático de nuestro país.

Para entender la valoración y el recuerdo de las mujeres republicanas en la actualidad, cabe establecer una evolución, porque la memoria está sometida a un cambio constante ${ }^{11}$. Primero, hay que partir de la política de la memoria del Franquismo, que fue del miedo a la Guerra y al caos de la República, que justificaba la rebelión de 1936, en las primeras décadas, a la insistencia en el progreso económico y los 25 años de paz en los años sesenta y setenta. ¿Cómo aplicar estos presupuestos a las mujeres? En el primer franquismo, desde las instancias oficiales y desde el discurso médico, hubo una demonización de las "rojas», no sólo política sino sobre todo moral, pues suponían un peligro para el modelo doméstico femenino franquista: según esta retórica, la decadencia de las costumbres en los años treinta obedeció al comportamiento de esas mujeres que habían mantenido relaciones sentimentales fuera del marco del matrimonio eclesiástico y habían decidido controlar el número de hijos que querían tener ${ }^{12}$.

Pero incluso se juzga moralmente su participación política en la República o en la resistencia durante el conflicto, caricaturizándolas con brutalidad como andróginas, feas, provocadoras o sabihondas, en lo que Sofía Rodríguez califica de violencia simbólica ${ }^{13}$. En la oratoria franquista, estas mujeres "masculinizadas» desprestigiaban a los combatientes republicanos y ponían en duda su virilidad $^{14}$. El psiquiatra militar Vallejo Nájera realizó estudios sobre las presas políticas, llegando a la conclusión de que debían ser aisladas de sus hijos y de la sociedad, para garantizar que su influencia perversa no perjudicara a la nueva España que la dictadura pretendía implantar en el país ${ }^{15}$. Frente a ellas se alzaba el modelo femenino propugnado por la Iglesia y la Sección Femenina,

11. JuliÁ, Santos, «Presentación» a JuliÁ, Santos (dir.), Memoria de la Guerra y del Franquismo, Madrid, 2006, p. 17.

12. Mary NASH describe el discurso de demógrafos y médicos en "Pronatalismo y maternidad en la España franquista", en BOCK, Gisela y THANE, Pat (eds.), Maternidad y políticas de género. La mujer en los estados de bienestar europeos, 1880-1950, Madrid, 1996, pp. 279-307.

13. RODRÍGUEZ LÓPEZ, Sofía, «Mujeres perversas. La caricaturización femenina como expresión de poder entre la guerra civil y el franquismo", Asparkía, n 16 (2005), pp. 177-198. También alude a las mujeres como enemigas deshumanizadas por la oratoria franquista SEVILLANO, Francisco, Rojos. La representación del enemigo en la guerra civil, Madrid, 2007, pp. 107-125.

14. RIPA, Yannick, «Féminin/masculin: les enjeux du genre dans l'Espagne de la Seconde République au franquisme", Le Mouvement Social, n 198 (2002), pp. 111-127. No obstante, cabe recordar que también desde el bando republicano se lanzaron críticas misóginas a las mujeres católicas y falangistas, debido a la extensión de los prejuicios de género (RODRíGUEZ LóPEZ, Sofía, op. cit.).

15. VINYES, Ricard, Irredentas. Las presas politicas y sus hijos en las cárceles franquistas, Madrid, 2002, pp. 49-70 y del mismo autor "Construyendo a Caín. Diagnosis y terapia del disidente: las investigaciones psiquiátricas de Antonio Vallejo Nájera con presas y presos políticos», Ayer, n ${ }^{\circ} 44$ (2001), pp. 227-250. 
caracterizado por la sumisión y la reclusión doméstica ${ }^{16}$. A partir de los años sesenta, estas mujeres, como otras referencias al pasado, desaparecen del discurso franquista y se difunde un nuevo patrón femenino, protagonizado por mujeres laboriosas, eficientes y consumidoras, pero religiosas y moralmente intachables, como sostienen Carmen Agulló o Carmen Romo ${ }^{17}$. El silencio cubrió las experiencias de las mujeres republicanas, sólo roto y de forma parcial en la privacidad de algunas familias de izquierda, y el olvido se extendión ${ }^{18}$.

En segundo lugar, en la Transición, más allá de la controversia sobre la existencia de un pacto de silencio o de una amnesia sobre la Guerra en el ámbito político ${ }^{19}$, puede afirmarse que la mayoría de las mujeres -destacadas o anónimas- de la República y la Guerra continuaron en el olvido, pues no en vano muchas habían muerto en el exilio ${ }^{20}$. Sin embargo, algunas dirigentes políticas empezaron a ser recordadas. Las visitas de Victoria Kent o Federica Montseny fueron saludadas en los medios de comunicación como símbolo del fin de la Guerra y su figura, en especial la segunda, reivindicada por colectivos políticos de izquierda. El personaje fundamental, en este sentido, fue Dolores Ibárruri, cuyo regreso definitivo encarnó de forma paradójica tanto el recuerdo de la Guerra como la reconciliación de los españoles, representada en el encuentro con Suárez en las Cortes ${ }^{21}$. En algunos colectivos, en especial el feminista, se reivindicó la memoria de las mujeres republicanas, y se publicaron memorias y

16. Existe una bibliografía extensa al respecto. Vid., entre otros trabajos, MOLINERO, Carme, «Mujer, franquismo y fascismo. La clausura forzada en un "mundo pequeño», Historia Social, $\mathrm{n}^{\circ} 30$ (1998), pp. 97-117; ROCA I GIRONA; Jordi, De la pureza a la maternidad. La construcción del género femenino en la postguerra española, Madrid, 1996; RicHMOND, Kathleen, Las mujeres en el fascismo español. La Sección Femenina de Falange, 1934-1959, Madrid, 2004.

17. AGUlló DíAz, $M^{a}$ del Carmen, "Transmisión y evolución de los modelos de mujer durante el franquismo (1951-1970)", en TRUjILLANO SÁNCHEZ, José Manuel y GAGO GONZÁLEZ, José María (eds.), Historia y memoria del franquismo, 1936-1978, Ávila, 1997, pp. 491-502; RoMO, Carmen, «Hacia un mercado común de los cuerpos. La utilización de los arquetipos femeninos como instrumentos para la promoción política en los años sesenta", Feminismo/s, n 2 (2003), pp. 59-78.

18. Como indica Josefina CUESTA, el silencio es distinto del olvido por cuanto hay elementos que son recordados por testimonios, pero no pasan a formar parte de la memoria porque la sociedad no es receptiva a esos discursos (Historia del presente..., pp. 54-55).

19. Alberto REIG TAPIA cree que hubo una amnesia (Memoria de la Guerra Civil. Los mitos de la tribu, Madrid, 1999, p. 352 y La cruzada de 1936. Mito y memoria, Madrid, 2006, pp. 25 y 375). Por el contrario, Santos Julí́ insiste en que la Guerra estuvo presente en el debate político y se publicaron numerosas obras sobre el conflicto ( Echar al olvido. Memoria y amnistía en la transición», Claves de Razón Práctica, n 129 (2003), pp. 14-24 y "Memoria, historia y política de un pasado de guerra y dictadura», en Julí́, Santos (dir.), op. cit., pp. 27-77). Por su parte, Paloma AGUILAR FERNÁNDEZ afirma que se habló del pasado en el terreno político, pero hubo un pacto de no instrumentalización del pasado; insiste en la presencia frecuente de la Guerra en el ámbito cultural y una demanda de consenso de la sociedad española (entre otras obras, en "La evocación de la Guerra y del Franquismo en la política, la cultura y la sociedad españolas», en JuliÁ, Santos (dir.), op. cit., pp. 279-317).

20. Entre otras, algunas tan destacadas en su momento como Clara Campoamor o Margarita Nelken.

21. CruZ, Rafael, Pasionaria. Dolores Ibárruri, historia y símbolo, Madrid, 1999, p. 221. 
unos primeros estudios ${ }^{22}$. Pero más allá de los ámbitos más politizados y feministas, y de algunos iconos como «Pasionaria», continuó el olvido. Esta circunstancia se observa en la literatura y el cine, que prestaron atención a la Guerra, pero poco a las mujeres, con excepción de las entrevistas a Dolores Ibárruri y a Federica Montseny recogidas en La vieja memoria (Jaime Camino, 1977) ${ }^{23}$.

Por último, en la democracia actual, como se ha comentado, existe un destacado interés social por la República, la Guerra y el Franquismo, debido entre otras causas al desarrollo de un derecho penal internacional que investiga las violaciones de derechos humanos, la estabilidad de la democracia, el cambio en la estrategia de los partidos y la llegada a la vida adulta de una nueva generación, la de los nietos ${ }^{24}$. Aróstegui insiste en que la generación actual se caracteriza por una memoria del dolor en una época en que se busca no el debate político sino la ejemplaridad humana, que se interesa por las víctimas sin nombre, los niños o el exilio ${ }^{25}$ : no lo menciona, pero también por las mujeres. En ese contexto, parte de la atención se dirige a las republicanas de los años treinta, desde una posición despolitizada, que parece asumir la tesis de que las mujeres fueron víctimas inocentes de la guerra.

Se trata de una sed de conocimiento centrada en las historias personales, el sufrimiento y el heroísmo individual. Esta circunstancia puede observarse en la literatura, los documentales y sobre todo en el cine que más popularidad han tenido, que están contribuyendo a crear una memoria colectiva determinada de la Guerra Civil26. Como indica Jünke, en el cine y la literatura la Guerra Civil se convierte en referencia común para buena parte de la sociedad española, en un «lugar de memoria» para una amplia comunidad, despolitizándola y descontextualizándola ${ }^{27}$. Sobre la literatura de ficción, Mainer señala que en algunos casos existe una "ternurización» del tema, que insiste en los sufrimientos y los recuerdos, en una primacía de lo sentimental sobre lo histórico, elementos

22. Por ejemplo, CAMPOAMOR, Clara, Mi pecado mortal. El voto femenino y yo, laSal, Barcelona, 1981 o GoICOECHEA, Maite, «Mujer y Guerra Civil: la historia que no se contó. Milicianas del 36, las olvidadas", Vindicación Feminista, n 26-27 (septiembre de 1978), pp. 51-54.

23. En la película también habla brevemente la militante del POUM Maria Rovira. Sobre este filme, Magí CRUSELls destaca, ente otros elementos, que incluye testimonios femeninos (La Guerra Civil española: cine y propaganda, Barcelona, 2000, p. 155).

24. AgUilar FernánDeZ, Paloma, "Presencia y ausencia de la guerra civil y del franquismo en la democracia española. Reflexiones en torno a la articulación y ruptura del 'pacto de silencio'", en ARÓstegui, Julio y GODICHEAU, François (eds), op. cit., pp. 272-273.

25. ARÓSTEGUI, Julio, "Traumas colectivos y memorias generacionales: el caso de la guerra civil», en ARóstegui, Julio y Godicheau, François (eds), op. cit., p. 90.

26. SÁnCHEZ-BiosCA, Vicente, Cine y Guerra Civil española. Del mito a la memoria, Madrid, 2006, p. 317. En el mismo sentido, $M^{a}$ Fátima Del Olmo RodríGueZ reclama la atención de los historiadores sobre las películas, como elementos que influyen en la construcción de un recuerdo público del pasado ("El 'recuerdo colectivo' del Holocausto a través del cine y la televisión: sus implicaciones para el historiador», en ForCADELL, Carlos y otros (eds.), Usos de la Historia y politicas de la memoria, Zaragoza, 2004, pp. 123-141).

27. JÜNKE, Claudia, "'Pasarán años y olvidaremos todo': la Guerra Civil española como lugar de memoria en la novela y el cine actuales en España", en WINTER, Ulrich (ed.), Lugares de memoria de la Guerra Civil y el franquismo. Representaciones literarias y visuales, Madrid, 2006, pp. 105-106. 
que caracterizan, en su opinión, La voz dormida de Dulce Chacón -que alude a experiencias femeninas en la Guerra y la represión franquista sobre las mujeres-, entre otros relatos ${ }^{28}$. La publicación de ensayos, con frecuencia obra de periodistas, en editoriales comerciales que realizan importantes campañas de promoción ${ }^{29}$, o en revistas divulgativas, y la profusión de documentales televisivos, reportajes y series de ficción que insisten en los elementos emotivos denotan ese interés social que, como indica Sánchez-Biosca, es convertido en consumo $^{30}$. El protagonismo de las mujeres en las películas actuales dedicadas a la Guerra es patente, basta recordar filmes de éxito como ¡Ay Carmela! (Carlos Saura, 1990), Tierra y Libertad (Ken Loach, 1996) o Libertarias (Vicente Aranda, 1996) ${ }^{31}$. Sobre la primera, Jünke mantiene que enfatiza lo moral e individual, no lo político, por lo que la película consigue convertirse en una referencia consensual $^{32}$. De las segundas nos ocuparemos más adelante.

Puede afirmarse, por tanto, que el silencio y el olvido sobre las mujeres republicanas han desaparecido. A ello ha contribuido la importancia concedida a lo sentimental y al testimonio de la gente corriente y las víctimas, propia de la época actual; además, en el caso de las mujeres, también se ensalza a las pioneras o heroínas individuales, pero subestimando su compromiso político y resaltando sus cualidades personales. Sánchez Biosca señala dos riesgos, en este sentido: el consumo emotivo de publicaciones o filmaciones y la identificación entre testimonio/memoria y verdad histórica ${ }^{33}$. Diversos autores han subrayado la diferencia entre memoria e historia. La memoria es reivindicación de un pasado y pretende legitimar, rehabilitar, honrar o condenar, mientras que la historia es un discurso construido, contrastable y objetivado, y busca

28. MAINER, José Carlos, «Para un mapa de lecturas de la Guerra Civil (1960-2000)», en JuliÁ, Santos (dir.), op. cit., pp. 155-156.

29. Textos escritos con mayor o menor fortuna. Entre otros, LAFUENTE, Isaías, Agrupémonos todas: la lucha de las españolas por la igualdad, Madrid, 2003; LOZANO, Irene, Federica Montseny. Una anarquista en el poder, Madrid, 2004; OLESTI, Isabel, Nou dones i una guerra: les dones del 36, Barcelona, 2005; QUIÑONERO, Llum, Nosotras que perdimos la paz, Madrid, 2005; LAFUENTE, Isaías, La mujer olvidada. Clara Campoamor y su lucha por el voto femenino, Madrid, 2006. Domingo, Carmen, Nosotras también hicimos la guerra. Defensoras y sublevadas, Madrid, 2006, VILLENA, Miguel Ángel, Victoria Kent. Una pasión republicana, Barcelona, 2007.

30. SÁNCHEZ-BIOSCA, Vicente, op. cit., pp. 16-18. A ello habría que añadir las memorias y autobiografías, los textos que recogen entrevistas o escritos de mujeres que vivieron esos acontecimientos (como el Colectivo Dones del 36) o las biografías elaboradas por Antonina RoDRIGo, que han sido editadas o reeditadas recientemente: Una mujer libre. Amparo Poch y Gascón, médica anarquista, Madrid, 2002; Mujer y exilio. 1939, Madrid, 2003; María Lejárraga, una mujer en la sombra, Madrid, 2005; Federica Montseny, 1905-1994, Barcelona, 2006.

31. Y en recreaciones cinematográficas de la represión de posguerra, con Silencio roto (Montxo Armendáriz, 2001), El laberinto del fauno (Guillermo del Toro, 2006) o sobre todo Las trece rosas (Emilio Martínez-Lázaro, 2007), muy vinculadas al interés por la guerra pero que exceden el marco cronológico estudiado en este texto. También el libro del periodista FONSECA, Carlos, Trece rosas rojas. La historia más conmovedora de la guerra civil, Madrid, 2005, del que cabe resaltar el refuerzo sentimental del subtítulo.

32. JÚNKE, Claudia, op. cit., pp. 106-110. A diferencia de Alberto REIG TAPIA, que la considera una parábola política (Memoria de la Guerra Civil. Los mitos de la tribu..., p. 65).

33. SÁNCHEZ-BIOSCA, Vicente, op. cit., p. 37. 
conocer, interpretar o explicar. Al margen de los valores que defienden y de que respondan a la falta de interés institucional en la reparación de las víctimas, en ocasiones los colectivos que reivindican la recuperación de la memoria pueden aproximarse a la mitificación ${ }^{34}$. De ahí que se advierta contra los abusos de la memoria, tanto de las víctimas ${ }^{35}$, como desde el poder ${ }^{36}$. Volviendo a las mujeres, ya no hay silencio ni olvido, pero no puede decirse que haya conocimiento riguroso del pasado.

Como en otros aspectos del pasado, este consumo de historias de mujeres marcha paralelo, con pocos cruces, con la investigación histórica. La historiografía ha evolucionado hacia un creciente interés por los nuevos sujetos históricos, sus actitudes y valores, por lo que está introduciendo los análisis sobre las mujeres ${ }^{37}$, proceso al que no es ajeno el desarrollo de la historia de género, muy atenta a la República y la Guerra Civil. Esta evolución parte en los años setenta desde posiciones mitificadoras de víctima/heroína, que reivindicaban desde el feminismo y el antifranquismo una primera recuperación de su memoria, en un contexto de búsqueda de referentes políticos anteriores al franquismo ${ }^{38}$. El interés se centró, sobre todo, en el voto femenino ${ }^{39}$. En los ochenta y noventa la historia de las mujeres superó esa primera visión, recordando la pluralidad de experiencias femeninas en los años treinta, y estableció un balance entre permanencia y cambio. Destacan las aportaciones de Mary Nash, que define la Guerra como catalizadora de una movilización femenina que amplió la presencia pública de las mujeres, pero sin romper con los papeles tradicionales de género $^{40}$. En la actualidad, también para la República Ana Aguado establece una valoración similar, de convivencia entre cambios y permanencias, afirmando que se dieron condiciones necesarias -avances legislativos- pero no suficientes - por la lentitud de los cambios de mentalidad- para un cambio en las relaciones de género ${ }^{41}$. Junto con estos balances generales, el interés por la individualidad

34. Aróstegui, Julio, La historia vivida..., pp. 163-165 y Julí́, Santos, «Presentación»..., p. 17.

35. TODOROV, Tzvetan, Los abusos de la memoria, Barcelona, 2000.

36. Ricoeur, Paul, La memoria, la historia, el olvido, Madrid, 2003, pp. 110-111.

37. BlANCO RODRíGUEZ, Juan Andrés, «El registro historiográfico de la guerra civil, 1936-2004», en ARÓstegui, Julio y GodicheAU, François (eds.), op. cit., p. 398 y Pérez Ledesma, Manuel, «La Guerra Civil y la historiografía: no fue posible el acuerdo", en JuliÁ, Santos (dir), op. cit..., pp. 130-133.

38. La evolución, aludiendo a los estudios sobre las mujeres en la Guerra, en NASH, Mary, Rojas. Las mujeres republicanas en la guerra civil, Madrid, 1999, pp. 28-34.

39. Con los estudios pioneros de CAPEL, Rosa, El sufragio femenino en la Segunda República española, Granada, 1975; SCANLON, Geraldine M., La polémica feminista en la España contemporánea (18681974), Madrid, 1976; FAGOAGA, Concha, Clara Campoamor. La sufragista española, Madrid, 1980. Un poco posterior es FAGOAGA, Concha, La voz y el voto de las mujeres, 1877-1931, Barcelona, 1985.

40. Además de Rojas..., abordó estos asuntos en Mujer y movimiento obrero en España, Barcelona, 1981, entre otras obras. También insiste en la pluralidad de vivencias femeninas GARCÍA-NieTO PARÍS, Maria Carmen, "Las mujeres en la guerra civil de España: nueva perspectiva", en Nuevas perspectivas sobre la mujer, Madrid, 1982, vol. I, pp. 184-189.

41. AgUADO, Ana, "Entre lo público y lo privado: sufragio y divorcio en la Segunda República», Ayer, nº 60 (2005), pp. 105-134. 
y la renovación de la biografía actuales han favorecido la publicación de numerosas semblanzas de mujeres destacadas en la República y la Guerra ${ }^{42}$.

\section{MITOS Y ESTEREOTIPOS EN FEMENINO}

La importancia de los mitos en la conformación de la memoria colectiva y la memoria social ha sido puesta de manifiesto en diferentes ocasiones. En el caso que nos ocupa, los mitos están en estrecha relación con la memoria de la República y la Guerra, que permanecen inamovibles al margen de los estudios historiográficos, como recuerda Reig Tapia ${ }^{43}$. Los mitos intentan explicar la realidad como una acción extraordinaria llevaba a cabo por protagonistas sobresalientes, individuales o colectivos, bajo un formato idealizado y sin atisbos de incertidumbre ${ }^{44}$. Además, proporcionan un modelo de valores y proyectan estructuras mentales o sociales ${ }^{45}$. En ese sentido, la memoria social y colectiva de la República y la Guerra se vincula a la extensión de derechos y a la movilización armada femenina, es decir, refuerza la idea del cambio experimentado por las mujeres, pero oculta las permanencias y las resistencias al mismo. Además, por paradójico que resulte, ofrece una visión desideologizada de este proceso e insiste en la identificación entre víctima pasiva y mujer. Al negar o dejar en un segundo plano elementos fundamentales de la realidad social y política, los mitos contribuyen a simplificar el recuerdo del pasado y a difundir una visión reduccionista del presente.

Algunos mitos políticos que surgieron en la República o la Guerra van perdiendo con el tiempo su carácter ideológico, adscrito a una determinada corriente o formación política, y adquieren contornos más sociales que políticos. Sin un estado que los reforzara y mantuviera, soportando la oratoria franquista que contribuyó a su simplificación y uniformización, y sobre todo a su olvido, y sin una unidad de criterios y valoraciones políticas, estos mitos permanecieron vivos sólo en algunos colectivos, en la clandestinidad y en el exilio, y volvieron a aflorar con la democracia, pero en un contexto que primaba el consenso y no el enfrentamiento político. En la actualidad, los mitos femeninos de la República y la Guerra han perdido sus perfiles ideológicos claros, para presentarse como mitos vinculados a una izquierda poco definida, e incluso a un amplio conjunto de la sociedad que se identifica emocionalmente con las víctimas anónimas o las heroínas sin un compromiso político definido. Los nombres empiezan a borrarse o a perder su carga ideológica, aunque para el comunismo la figura de Dolores Ibárruri, para el anarquismo Federica Montseny o para el feminismo Clara Campoamor sigan siendo referencias propias.

42. Entre otras, Preston, Paul, Palomas de guerra. Cinco mujeres marcadas por el enfrentamiento bélico, Barcelona, 2001, TAVERA, Susana, Federica Montseny. La indomable, Madrid, 2005; AVILÉS FARRé, Juan, Pasionaria. La mujer y el mito, Barcelona, 2005.

43. REIG TAPIA, Alberto, "Los mitos políticos franquistas de la guerra civil y su función: el 'espíritu' del 18 de julio de 1936", en ARÓSTEGUI, Julio y GodiCHEAU, François (eds.), op. cit., p. 216.

44. Moradiellos, Enrique, 1936. Los mitos de la Guerra Civil, Barcelona, 2004, p. 19.

45. REIG TAPIA, Alberto, La cruzada de 1936..., p. 124. 
Frente al componente emotivo del mito, otros elementos que perviven sobre las mujeres de la República y de la Guerra se ajustan más al concepto de estereotipo, entendido como imagen o idea aceptada comúnmente por un grupo con carácter inmutable, según el diccionario de la RAE. La extendida creencia en la historia como un continuo avance lineal y por tanto la confianza en el exclusivo paso del tiempo hacia un futuro mejor contribuyen a reforzar estereotipos en torno a las complejas realidades del pasado y del presente. Se trata de mitos y estereotipos tanto políticos como de género, que seleccionan y manipulan el pasado, que refuerzan algunos elementos y olvidan otros muchos. En fin, mitos y estereotipos cuyo éxito reside en presentar de forma sencilla y a veces maniquea la realidad histórica, plural y contradictoria. Los esfuerzos de la historiografía por ofrecer una interpretación más rigurosa del pasado en ocasiones no es admitida, no sólo por colectivos afines al franquismo, sino en una medida distinta por algunos sectores de izquierda, que se resisten a aceptar que la crítica a los republicanos no significa una desvalorización de los muchos avances que la República introdujo. Pero además de identificar los mitos y lugares comunes sobre las mujeres republicanas de los años treinta, nos interesa poner de manifiesto por qué han pervivido o se han reforzado en la actualidad.

El primer mito que vamos a analizar es la identificación entre republicanismo y voto femenino. La República suele ser reconocida como un régimen de libertades, que beneficiaron a las mujeres. La Constitución de 1931 recogió por primera vez en la historia de España el derecho al sufragio femenino, debido a las demandas feministas y también por coherencia democrática. La figura de Clara Campoamor, en este sentido, empieza a ser identificada socialmente como la impulsora del voto femenino. Sin embargo, fuera de los ámbitos especializados, no siempre se conoce la controversia que trajo consigo esta medida en el seno de la izquierda, que ha sido puesta de manifiesto por la historiografía de género ${ }^{46}$, olvido que contribuye a mitificar al republicanismo. En efecto, en el debate parlamentario y en los medios de comunicación, los partidos republicanos se mostraron contrarios al sufragio femenino: como señala Ana Aguado, se consideraba a las mujeres "iguales pero no tanto» ${ }^{47}$. Los argumentos feministas e igualitarios fueron defendidos por Clara Campoamor, del Partido Radical, en contra del parecer de su partido ${ }^{48}$ - «la única manera de madurarse para el ejercicio de la libertad y de hacerla accesible a todos es caminar dentro de ella»-o por el socialista Manuel Ovejero, frente a los cuales se esgrimieron razones de tipo político y también prejuicios de género ${ }^{49}$. La republicana radical-socialista Vic-

46. Además de las citas de la nota 38, vid. CAPEL, Rosa, «El sagrado derecho de votar», en MORANT, Isabel (dir.), Historia de las mujeres en España y América Latina, vol. IV, Madrid, 2006, pp. 77-100.

47. AGUADO, Ana, op. cit., p. 112.

48. Todo lo cual le hacía aparecer como trasgresora (NASH, Mary, "La transgresión de la ciudadanía en femenino: Clara Campoamor y Federica Montseny», en GómeZ BLESA, Mercedes (ed.), Las intelectuales republicanas. La conquista de la ciudadanía, Madrid, 2007, pp. 39-46).

49. Como señala Mary NASH, se debatía entre dos conceptos de ciudadanía: la igualitaria o la diferenciada, que restringía los derechos de las mujeres ("Género y ciudadanía", Ayer, nº 20 (1995), pp. 241-258). 
toria Kent, aunque personalmente estuviera convencida de la capacidad de la mujer para participar en la vida pública, utilizó un razonamiento político muy extendido en la época, al considerar que era precipitado aprobar este derecho, aludiendo al analfabetismo femenino y a la influencia clerical sobre las mujeres -en su opinión, era una cuestión "de oportunidad para la República»-.

Otros diputados republicanos, sin embargo, expresaron prejuicios de género para negar el derecho de voto femenino. El médico galleguista Novoa Santos afirmó que la mujer estaba dominada por las emociones y el sentimentalismo, no por la razón, por lo que no estaba preparada para intervenir en la vida política con independencia de criterio. El miembro del Partido Republicano Federal Manuel Ayuso propuso que sólo se concediera el derecho a voto a las mujeres mayores de cuarenta y cinco años, al considerar que la mujer era deficiente en voluntad y en inteligencia hasta cumplir dicha edad, cuando abandonaba la edad fértil. Osorio y Gallardo, que pertenecía a la Agrupación al Servicio de la República y después ingresó en Izquierda Republicana, planteó que sólo pudieran ejercer este derecho las mujeres solteras y viudas, pues a su juicio el voto de la mujer casada podría provocar disputas conyugales. Por último, el radical Guerra del Río sugirió que el sufragio de la mujer se supeditara a una ley electoral que podía ser revocada si la mujer votaba por los partidos conservadores. Estas propuestas fueron rechazadas, pero reflejan el sentir de buena parte del republicanismo español del momento, marcado por el anticlericalismo y por la consideración de que la política no era un espacio propio para las mujeres ${ }^{50}$, en un contexto en que otros diputados defendieron el voto femenino, sobre todo socialistas - pero también conservadores, algo que tampoco suele ser de dominio público-. De hecho, la aprobación de la igualdad entre hombres y mujeres en el ejercicio del derecho al sufragio, se consiguió a pesar de los votos en contra de los diputados de Acción Republicana, el Partido Radical Socialista y el Partido Radical, con la excepción de Campoamor y otros pocos.

Aunque la historiografía ya había estudiado este proceso desde los ochenta y primeros noventa, el interés renovado por las mujeres en la República ha favorecido la publicación de otros textos, en ocasiones firmados por periodistas $^{51}$. En algunos colectivos progresistas, el descubrimiento de esa contradicción del republicanismo crea incomodidad al no admitirse la posibilidad de que los republicanos pudieran mantener posturas mediatizadas por los prejuicios. En ocasiones acaba justificándose la actuación de los diputados republicanos con el argumento de la escasa preparación de las mujeres, lo cual denota que pervive

50. Vid. SALOMÓN CHÉLIZ, Pilar, «Las mujeres en la cultura política republicana: religión y anticlericalismo", Historia Social, n 53 (2005), pp. 103-118 y SANFelIU, Luz, Republicanas. Identidades de género en el blasquismo (1895-1910), Valencia, 2005.

51. Domingo, Carmen, Con voz y voto. Mujer y politica en España, 1931-1945, Barcelona, 2004, quien afirma: "no pretendo, pues, suplir la voz del historiador con este libro, sino acercar esta parte de la historia de España a un público más amplio, al que hasta ahora le ha sido más difícil acceder a este tipo de textos» (p. 29). 
la desconfianza en la participación política de las mujeres, o que la extensión de derechos se considera menos importante que otros elementos políticos.

En relación con lo anterior, un estereotipo muy extendido es la culpabilización de las mujeres por el triunfo conservador en 1933, en las primeras elecciones en que las mujeres pudieron ejercer el derecho de voto. Ya en la época se apuntó este hecho, como confirmación de los temores de 1931. Por supuesto, parte del electorado femenino votó a la derecha, al igual que muchos varones, pero también hubo otros factores que explican el resultado electoral, como la desunión de la izquierda, la llamada a la abstención del anarquismo o la reorganización de la derecha ${ }^{52}$. De hecho, las mujeres también votaron en febrero de 1936 y ganó el Frente Popular, aunque no se suele aludir a este hecho. En el fondo, como señalaba Clara Campoamor ya en 1936, se están respaldando con ello las posiciones en contra del sufragio y se refuerza la idea de la política como un ámbito ajeno a las mujeres ${ }^{53}$.

También puede calificarse de estereotipo la creencia en que el derecho de voto significó la plena integración de las mujeres en la vida política. Es cierto que la obtención de este derecho promovió la creación de organizaciones políticas femeninas, autónomas -la Unión Republicana Femenina de Clara Campoamor, la Acción Política Femenina Independiente de la Asociación Nacional de Mujeres Españolas, Mujeres contra la Guerra y el Fascismo o la anarquista Mujeres Libres-o en los partidos políticos-PSOE, partidos republicanos, pero también en Acción Popular y en Falange-. Asimismo, cobró gran dinamismo la prensa de mujeres en que se trataba de política, es decir, se desarrolló un espacio de debate político en femenino ${ }^{54}$. Sin embargo, la participación política femenina será bastante reducida. Sólo hubo nueve diputadas en todas las legislaturas republicanas y muchas mujeres, en especial de ámbito rural o bajo nivel cultural, nunca llegaron a votar siquiera ${ }^{55}$. El discurso político, como se observa en la propaganda electoral, seguirá ignorando a las mujeres como individuos, supeditándoles a su condición de madres y esposas, tanto entre los partidos conservadores como entre los progresistas ${ }^{56}$. No puede confundirse, en consecuencia, legalidad con realidad, ni olvidarse las resistencias a la presencia femenina en la vida política.

52. VILLALAÍN GARCÍA, Pablo, La participación de la mujer en las elecciones generales celebradas en Madrid durante la II República (1931-1936), Madrid, 2000.

53. Campoamor, Clara, Mi pecado mortal. El voto femenino y yo, Madrid, 1936, pp. 245-264.

54. BUSSY-GENEVOIS, Danielle, "Historia de una mayoría ciudadana. Ciudadanía femenina y Segunda República», en AGUADO, Ana (coord.), Las mujeres entre la historia y la sociedad contemporánea, Valencia, 1999, pp. 129-131.

55. Existen diversos testimonios de ello. Por ejemplo, Palmira Galiano afirma: «Ay, hija, eso eran cuatro rojas allí en Madrid. Aquí no nos enteramos" (cit. en Simón RodríGUEZ, María Nieves, "Lo personal es político», en La transición a la democracia en Alicante (1974-1982), Alicante, 2006, p. 220).

56. NASH, Mary, «Política, condició social i mobilització femenina: les dones a la Segona República i a la Guerra Civil», en NASH, Mary (a cura de), Més enllà del silenci: les dones a la història de Catalunya, Barcelona, 1988, p. 250. 
En el mismo sentido, sin negar avances fundamentales como el derecho al divorcio, la supresión del delito de adulterio o la igualdad entre niños ilegítimos y legítimos, entre otras muchas medidas, no suelen ser conocidas otras disposiciones menos igualitarias de la República. Por ejemplo, el código civil seguía considerando al marido como representante legal de la mujer casada, aquél podía disponer del salario de su esposa y era necesaria su autorización para que ésta firmara un contrato. La condición femenina era motivo de exclusión en algunos trabajos -nocturnos, insalubres o peligrosos, fiscalía o judicatura-, a pesar de que se había reconocido el derecho a la igualdad en el acceso a los puestos de trabajo ${ }^{57}$. El alumnado femenino se incrementó, pero, al contrario de lo que se suele afirmar, no se implantó la coeducación en la enseñanza y sólo en algunas ocasiones la enseñanza mixta ${ }^{58}$. Más allá de las razones que puedan explicar estas circunstancias, lo que interesa destacar es su olvido o negación. Entre algunos sectores de izquierda que reivindican la memoria de la República desde posiciones mitificadoras, se considera que las mujeres consiguieron con la democracia republicana derechos más adelantados incluso que en la actualidad. Además, se oculta la pluralidad de experiencias y realidades femeninas, y la distancia entre las iniciativas de mujeres de clase media urbana en torno a instituciones como el Lyceum Club o la Residencia de Señoritas, y la pervivencia del discurso de la domesticidad entre muchas otras mujeres de diferentes extracciones sociales y ámbitos geográficos ${ }^{59}$. Frente a ello, se trata de valorar las luces y sombras de una etapa que, en conjunto, supuso un gran avance en la construcción de una sociedad moderna, democrática y más justa, pero tuvo sus límites ${ }^{60}$. Sin embargo, la importancia simbólica de estas transformaciones puede explicar su pervivencia en la memoria colectiva.

Durante la Guerra Civil, la construcción de mitos en torno a algunas vivencias o personajes femeninos fue muy destacada, en un contexto de intensa propaganda política. En el bando republicano, el más poderoso fue el de las milicianas, que se convirtieron en símbolo de la revolución y la resistencia antifascista. Como ha estudiado Mary Nash, la imagen de la miliciana cobró una gran importancia en la propaganda oficial, en los carteles que llamaban al alistamiento en los primeros meses de la contienda, dirigidos en especial a los varones y que presentaban un prototipo femenino atractivo. Las milicianas proyectaban una imagen nueva, de mujeres activas y resueltas, que vestían mono o pantalones, tomaban las armas y acudían al frente ${ }^{61}$. En la Guerra, algunas milicianas se convirtieron en iconos muy populares y elementos de

57. AGUADO, Ana y RAMOs, Ma Dolores, La modernización de España (1917-1939). Cultura y vida cotidiana, Madrid, 2002, pp. 214 y 218-219.

58. CORTADA ANDREU, Esther, Escuela mixta y coeducación en Cataluña durante la II República, Madrid, 1988.

59. AGUADO, Ana, op. cit., pp. 133-134.

60. Ibidem, p. 128 y YUSTA, Mercedes, "La Segunda República: significado para las mujeres", en MORANT, Isabel Morant (dir.), op. cit., pp. 107-110.

61. NASH, Mary, Rojas..., pp. 93-98; de la misma autora «La miliciana: otra opción de combatividad femenina antifascista", en Las mujeres y la Guerra Civil española, Madrid, 1991, pp. 97-108. 
referencia política, como Aida Lafuente -que en realidad había muerto en octubre de 1934-, Lina Odena -joven dirigente comunista que se suicidó en 1936 para no caer en manos del enemigo- o Rosario La Dinamitera -que perdió una mano con un explosivo-, a quienes se dedicaron numerosos poemas ${ }^{62}$. Estos nombres bautizaron calles, agrupaciones políticas y batallones militares. Los cantos a las mujeres armadas se reforzaban con las alusiones a otros mitos del pasado, como Agustina de Aragón ${ }^{63}$. Ya en la democracia, de nuevo irrumpió el mito de las milicianas, alimentado por el cine, con películas como Libertarias o Tierra y Libertad, que insisten en la camaradería entre milicianos y milicianas por encima de los prejuicios de género, o por textos y biografías de periodistas sobre algunas de estas figuras míticas ${ }^{64}$. De hecho, todavía hoy la imagen de la miliciana marchando al frente simboliza la Guerra Civil.

La consolidación de la historia de género y el desarrollo de un enfoque social de la Guerra han contribuido a un mejor conocimiento de las prácticas femeninas en el conflicto. Al margen del mito y de algunas experiencias reales, con frecuencia las milicianas siguieron desempeñando tareas consideradas femeninas en el frente -limpieza, cocina, auxilio sanitario- y muchas veces se encontraron con el paternalismo e incluso rechazo de sus compañeros de armas. Por otro lado, fue una experiencia bastante corta en el tiempo. En otoño de 1936, el gobierno de Largo Caballero reclamó el regreso de las milicianas a la retaguardia, bajo el lema «Los hombres al frente, las mujeres a la retaguardia", señalándose su escasa preparación militar. Pronto cambia la imagen que se proyecta de la miliciana en la propaganda, dejando de ser símbolo de la resistencia para pasar a ser identificada con la prostitución y la extensión de las enfermedades venéreas ${ }^{65}$.

Un segundo mito fundamental en el transcurso de la Guerra se gestó en torno a la figura de Dolores Ibárruri. Esta dirigente comunista simbolizó la resistencia antifascista no sólo para los miembros del PCE, sino para toda la izquierda. Su presencia era constante en la prensa, la radio los mítines políticos

62. Entre otras, a Aida Lafuente se le dedicaron estos versos «Ven, porque estaba manchada de España,/ ven, porque era la novia de Octubre, / ven, porque era la rosa de Octubre,/ ven, porque era la novia de España». A Lina Odena: "Así son nuestras mujeres,/ las de España forjante,/ todas como Lina Odena,/ defienden las libertades». Y Miguel Hernández a Rosario La Dinamitera: «Rosario, dinamitera,/ puedes ser varón y eres/ la nata de las mujeres,/ la espuma de la trinchera» (todas las citas en RAMOS-GASCón, Antonio (ed.), El Romancero del Ejército Popular, Madrid, 1978, pp. 71, 82 y 86, respectivamente).

63. Por ejemplo, «Madrileñas, ja las armas!/ Agustina de Aragón,/ bravas hembras de Numancia,/ de Cádiz y de Gerona,/ heroicas hijas de España:/ abandonad vuestras tumbas,/ escuchad nuestras llamadas/y dadnos vuestro heroísmo/ para ganar la batalla» (Ibidem, p. 107).

64. FOnSECA, Carlos, Rosario dinamitera. Una mujer en el frente, Madrid, 2001. Vid. también la obra de la historiadora CARABíAs ÁlVAro, Mónica, Rosario Sánchez Mora, la dinamitera. Historia de una mujer soldado en la Guerra Civil española, Madrid, 2001.

65. NASH, Mary, Rojas..., pp. 159-174. Esa identificación entre milicianas y prostitutas continúa muy arraigada en la actualidad, como se puede comprobar en algunas de las cartas al director publicadas por La Vanguardia sobre la película Libertarias (recogidas en Film-Historia, vol. VI, n ${ }^{\circ}$ 3, 1996, pp. 300-309). 
o en poemas ${ }^{66}$, su nombre era recurrente en calles y organizaciones políticas y militares. Junto a la creciente importancia del partido comunista en la Guerra, la construcción de este icono se fundamenta también en su capacidad oratoria y para difundir eslóganes («mejor morir de pie que vivir de rodillas», "no pasarán»), su físico, sus orígenes humildes, su apariencia de mujer de pueblo, y por encarnar a las madres que entregaban a sus familiares a la guerra ${ }^{67}$. A pesar de la demonización que experimentó su imagen por parte de la dictadura, en la clandestinidad continuó su mitificación, como símbolo de la lucha por la justicia y la resistencia, un mito que como indica Avilés ayudó a muchos a sobrevivir en condiciones extremas de resistencia antifranquista ${ }^{68}$.

En la Transición a la democracia su imagen reapareció públicamente, al grito de "Sí, sí, sí, Dolores a Madrid», que reclamaba su regreso, que tuvo lugar en mayo de 1977. En esta etapa se convirtió en emblema de la reconciliación, con su presencia en las Cortes, a pesar de que muchas veces en sus discursos y entrevistas aludía a la guerra o a la URSS, no a la España de los años setenta o al eurocomunismo ${ }^{69}$. No obstante, pronto pasó a un segundo plano en la actualidad mediática, aunque seguía participando en actos públicos del partido y era el centro de atención en homenajes, biografías y entrevistas. En la época, algunas mujeres comunistas caracterizadas por su combatividad eran denominadas "Pasionaria». Todo ello inmortalizó su imagen luchadora, elaborada por el PCE, aunque su figura despertaba interés más allá de los círculos comunistas. En palabras de Cruz, encarnó al pueblo, al PCE, a la madre, personificó la lucha por la libertad, la justicia y la dignidad, y como protagonista de la guerra «representó, para sus adversarios y seguidores, el símbolo principal del conflicto ${ }^{70}$.

Menos impacto en la memoria social española tuvo Federica Montseny, aunque su figura adquiriera tintes míticos para algunos sectores el anarquismo español. Como señala Tavera, ya durante la Guerra Civil, Montseny, a pesar de ocupar el cargo de Ministra de Sanidad y Asuntos Sociales y de convertirse así en la primera ministra mujer en la historia de España, no tuvo la popularidad de Ibárruri: por su físico, por las divisiones del movimiento anarquista o por su discurso revolucionario no consiguió convertirse en un mito ampliamente reconocido en el bando republicano. Además, en la Transición, el anarquismo era ya muy minoritario; aunque realizó viajes a España en los años setenta y ochenta, participó en programas televisivos y entrevistas o se publicaron sus memorias, acabó convertida en mito sólo en el ámbito libertario, si bien formó parte de las mujeres cuya memoria se recuperó ${ }^{71}$. Ambas continuaron siendo figuras de

66. Por ejemplo, de Miguel Hernández : «mujer, España, madre en infinito,/ eres capaz de producir luceros,/ eres capaz de arder de un solo grito» (en RAMOS-GASCÓn, Antonio (ed.), op. cit., p. 88).

67. RIPA, Yannick, «Le mythe de Dolores Ibarruri», Clio, nº 5 (1995) en http://clio.revues.org/sommaire29.html.

68. AVILÉS, Juan, op. cit., p. 188. Vid. también CRUZ, Rafael, op. cit., pp. 131-139 y 171-177.

69. CruZ, Rafael, op. cit., p. 221 y AVILÉS, Juan, op. cit., pp. 242-243.

70. CRUZ, Rafael, op. cit., pp. 226-236 y 241-242. Vid. AVILÉS, Juan, op. cit., p. 247.

71. TAVERA, Susana: op. cit., pp. 275-289. 
primer orden en sus respectivos movimientos, pero para la sociedad española perdieron esa identidad política tan marcada.

La actuación de las anarquistas, como protagonistas de la guerra, se ha convertido en otro mito en la memoria sobre la Guerra Civil. Su actividad, por ejemplo en torno a la organización Mujeres Libres, es más recordada que otros grupos mucho más extendidos, como Mujeres Antifascistas, de carácter plural aunque con fuerte impronta comunista ${ }^{72}$. Quizá esta circunstancia se pueda explicar por el discurso feminista y más rupturista de Mujeres Libres, por la mitificación de las experiencias y propuestas anarquistas -colectivizaciones, liberatorios de prostitución- o por el descrédito actual del comunismo. El éxito de la película Libertarias probablemente radica en ello. Este filme ha sido objeto de juicios negativos desde la historiografía o la crítica literaria ${ }^{73}$ : se le acusa de ofrecer una visión romántica y maniquea de la Guerra ${ }^{74}$, y de presentar frecuentes anacronismos, hasta el punto de que bajo la apariencia de reivindicar el pasado, en realidad supone una anulación del mismo ${ }^{75}$. Además, se insiste en que Libertarias potencia la idealización y heroización de las anarquistas, que favorece la identificación personal -no ideológica- con los personajes y presenta la guerra como una época ya pasada ${ }^{76}$. Helena López hace una lectura en clave de género de la película, al analizar los personajes femeninos, que cree desvirtuados -monja inocente, prostitutas lascivas, milicianas masculinizadas-; esta autora concluye que la película «romantiza lo político, lo anula por tanto, sin estar en el fondo a favor ni de unos ni de otros» ${ }^{77}$. Las protagonistas son heroínas primero y, tras su muerte violenta, víctimas ${ }^{78}$, doble característica que contribuye a explicar la popularidad de la película. El debate social que provocó enfrentó a partidarios de las tesis críticas anteriores con defensores de la veracidad del filme o de "usar las anarquistas de la época como referencia de una lucha igualitaria que las mujeres siempre hemos reclamado» ${ }^{79}$.

Frente a la mitificación de las anarquistas, la historiografía especializada ha señalado que la agrupación de Mujeres Antifascistas estuvo compuesta por

72. Sobre Mujeres Libres, vid. NASH, Mary, Rojas..., pp. 109-144 y de la misma autora Mujeres Libres: España, 1936-1939, Barcelona, 1976. También ACKELSBERG, Martha A., Mujeres Libres. El anarquismo y la lucha por la emancipación de las mujeres, Barcelona, 1999.

73. Sin embargo, Alberto REIG TAPIA lo considera una película valiente, que aborda con maestría y dignidad el complejo asunto del papel de los anarquistas y las mujeres en la Guerra (Memoria de la Guerra Civil..., p. 65).

74. AgUILAR FERNÁNDEZ, Paloma, «Romanticisme i maniqueisme en la guerra civil: de Tierra y Libertad a Libertarias", L'Avenç, no 204 (1996), pp. 66-70.

75. SÁNCHEZ-BIOSCA, Vicente, op. cit., p. 296.

76. JÜNKE, Claudia, op. cit.,pp. 110-114.

77. LóPEZ, Helena, «Mujer, violencia, espectáculo: la guerra civil española en libertarias (1996) de Vicente Aranda", en http://www.sens-public.org/spip.php?article173.

78. Magí CRUSELLS apunta que la muerte violenta de las protagonistas las mitifica; también afirma que el filme induce a pensar que todas las mujeres quisieron ir a luchar, cuando fueron sólo una minoría (op. cit., pp. 248 y 251).

79. Al menos así se refleja en las Cartas al Director de La Vanguardia (en Film-Historia, vol. VI, nº 3, pp. 300-309). 
unas 60.000 militantes, mientras Mujeres Libres consiguió afiliar a unas 20.000 mujeres. Por otra parte, Mujeres Libres no representaba el sentir más extendido entre los ácratas, sino al contrario una postura minoritaria, frente a posiciones que supeditaban las demandas feministas a la revolución, defendidas entre otros por la propia Federica Montseny. Además, en la práctica, si Mujeres Antifascistas contribuyó a movilizar a las mujeres en las tareas de retaguardia vinculadas a sanidad o confección de ropa, Mujeres Libres acabó haciendo lo mismo y priorizó los intereses de clase y de lucha antifascista sobre la conciencia de género ${ }^{80}$. Por otro lado, socialistas y republicanas, incluso las conocidas durante la República, en la Guerra pasan a un segundo plano. Todas ellas son denominadas «republicanas» y sobre todo «rojas», imagen que uniformiza la pluralidad política realmente existente, y que continúa bajo las diatribas franquistas hasta llegar al presente, difuminándose así los perfiles ideológicos de estas mujeres y despolitizándose su trayectoria ${ }^{81}$.

Tanto el mito de Dolores Ibárruri como el de las libertarias han contribuido por un lado a invisibilizar a otras activistas políticas destacadas como Margarita Nelken, Encarnación Fuyola, Emilia Elías, Constancia de la Mora, Matilde Huici, Aurora Arnáiz, Teresa Pàmies, Dolors Bargalló o Magda Donato, entre tantas otras ${ }^{82}$. Pero también, y de forma paradójica, han reforzado una imagen de participación femenina en igualdad de condiciones con los varones, cuando fueron mujeres que ocuparon un espacio en la política a pesar de que el contexto era muy adverso. En este sentido, un estereotipo muy extendido reside en la creencia en que la Guerra supuso una revolución, un cambio trascendental y profundo en la vida de las mujeres. Es cierto, como han puesto de manifiesto especialistas como Mary Nash, que la Guerra se convirtió en un catalizador de la movilización femenina y que "ensanchó los horizontes de la actividad femenina y se abrieron nuevos espacios de actuación pública», pero no hubo una revolución en las relaciones de género, no supuso «necesariamente una ruptura con la tradicional división sexual del trabajo» ni «forzosamente un cambio sustancial» en la mentalidad tradicional sobre la mujer ${ }^{83}$.

Analicemos con un poco más de atención estos elementos. En el bando republicano, la participación femenina en la Guerra tuvo lugar sobre todo en la retaguardia y fue decisiva en la resistencia de la población civil. Pero dicha

80. Gómez-Ferrer Morant, Guadalupe, "República y guerra civil: una perspectiva de género», en JULIÁ, Santos (coord.), Historia de España Menéndez Pidal, Tomo XL. República y guerra civil, Madrid, 2004, p. 552.

81. MOREnO SECO, Mónica, «Republicanas y República en a guerra civil: encuentros y desencuentros», Ayer, no 60 (2005), pp. 165-195.

82. A pesar de que sobre algunas hay publicaciones recientes. Una biografía de Constancia de la Mora en DE LA FuENTE, Inmaculada, La roja y la falangista. Dos perfiles de la España del 36, Barcelona, 2006; contamos también con la reedición de sus memorias (Doble esplendor, Madrid, 2004). Teresa PÀMIES ha publicado varios textos autobiográficos, entre las últimas versiones Memòries de guerra i d'exili, Barcelona, 2000.

83. NASH, Mary, "Republicanas en la Guerra civil: el compromiso antifascista», en MORANT, Isabel (dir.), op. cit., pp. 126-127. 
movilización obedeció a las necesidades bélicas y no a una toma de conciencia de género ${ }^{84}$ y se fundamentó en el discurso del maternalismo social. En la propaganda se reforzó la identificación entre mujeres y maternidad para incitarles a colaborar con la ayuda a los soldados y refugiados, por un futuro mejor para sus hijos: eran "madres combativas» y "heroínas de la retaguardia» ${ }^{85}$. Además, toda esta actividad estuvo vinculada a espacios tradicionalmente considerados femeninos, como la enseñanza o el cuidado -confección de ropa de abrigo para los combatientes, envío de alimentos al frente, trabajo en hospitales y centros de refugiados-. No obstante, según Nash estas tareas tradicionalmente femeninas obtuvieron en el contexto de la guerra connotaciones distintas y supusieron una revalorización pública de este tipo de actividades y de las mujeres que los desempeñaban ${ }^{86}$.

También fue destacada la incorporación de mujeres al trabajo en las fábricas y el campo, al sustituir a los hombres que iban al frente, para mantener el ritmo de producción. Pero una vez más cabe recordar que estas trabajadoras encontraron muchas resistencias entre sus compañeros, por el peso de los estereotipos tradicionales y porque se les consideraba competidoras en el mercado laboral. Además, no obtenían la misma remuneración por el mismo trabajo, no accedían a puestos de responsabilidad laboral y con frecuencia no se les permitía intervenir en las decisiones que marcaban el rumbo de los talleres o las colectividades agrícolas. Tampoco la despenalización del aborto en diciembre de 1936, con la importancia que tuvo la medida, supuso un cambio fundamental en la vida de las mujeres, que siguieron recurriendo en su mayor parte al aborto clandestino, debido al tabú social, al desconocimiento de esta disposición y a la negativa de muchos médicos a aplicarla ${ }^{87}$. En el mismo sentido, el proyecto de creación de liberatorios de prostitución del ministerio de Federica Montseny no tuvo repercusiones prácticas destacadas. En suma, debe subrayarse la presencia femenina en espacios nuevos y el entusiasmo de muchas mujeres en el compromiso político y la resistencia en la retaguardia -que fue decayendo a medida que la guerra avanzaba, por el desgaste moral y la necesidad de garantizar la supervivencia familiar ${ }^{88}$-, pero sin olvidar que en esencia las relaciones de género siguieron marcadas por pautas tradicionales y desiguales, y que no se dio una ruptura en la definición de la identidad femenina, identificada con la domesticidad.

84. GÓMEZ-FERRER MORANT, Guadalupe, op. cit., p. 559.

85. NASH, Mary, Rojas..., p. 99.

86. NASH, Mary, «Republicanas en la Guerra civil..., p. 141.

87. NASH, Mary, "Género, cambio social y la problemática del aborto», Historia Social, n² 2 (1988), pp. 19-35.

88. La obra de SeIDMAn, Michael, A ras de suelo. Historia social de la República durante la Guerra Civil, Madrid, 2003 insiste en este tipo de experiencias y hace una crítica infundada a los estudios de género, que, a su juicio, dan por supuesto una identidad común y olvidan la disidencia individual (p. 351). Por el contrario, precisamente la historia de género insiste en la heterogeneidad de experiencias de las mujeres (en plural), frente a la uniformidad de los estereotipos sobre la mujer (en singular). 
Por último, cuando se evoca la Guerra con frecuencia se subraya la presencia de mujeres entre las víctimas, que son encarnadas por una madre con sus hijos, imagen constante en fotografías, carteles u obras artísticas, como el "Guernica» de Picasso ${ }^{89}$. Si consideramos que reducir la pluralidad de experiencias femeninas a las figuras heroicas es una simplificación de la realidad histórica, lo mismo cabe decir de la identificación entre mujeres y víctimas inocentes, un estereotipo que refuerza la exclusión de las mujeres de los sujetos activos de la historia. Por supuesto, entre los ataques indiscriminados a la población civil, que consagró en buena cuenta la Guerra Civil española, una importante parte de las víctimas eran mujeres. Pero debe recordarse que en ambos bandos mujeres politizadas (y no politizadas) fueron objeto de represión, y que por tanto sufrieron depuración, maltrato o encarcelamiento. Soportaron violencia, pero fueron tan poco (o tan) inocentes como los varones que padecieron el mismo destino. Además, las mujeres participaron en actos violentos e incitaron a la violencia, en sacas de las cárceles, asaltos a las iglesias o linchamientos, aunque sea un aspecto poco estudiado. La identificación entre violencia y masculinidad las excluye de estos episodios tanto en la época como en la memoria actual ${ }^{90}$, volcando sobre la realidad histórica o presente estereotipos que la desvirtúan.

\section{CIUDADANÍA FEMENINA REPUBLICANA Y DEMOCRACIA ACTUAL}

Los mitos y estereotipos analizados constituyen una memoria en femenino que refuerza la idea del cambio experimentado por las mujeres, sin atender a las permanencias y las resistencias al mismo. Además, fortalece la creencia en que estas transformaciones llegan de forma natural, por el progreso histórico de toda sociedad, pasando por alto la involución franquista, y silenciando las luchas y demandas feministas o la importancia de una legislación igualitaria. Pérez Garzón recuerda que la memoria favorece la cohesión y la identidad de un grupo, pero desde situaciones de jerarquía social que reproducen relaciones sociales desiguales ${ }^{91}$. En este sentido, esa memoria de las mujeres republicanas influye en la percepción actual sobre la presencia femenina en la sociedad española, en un doble sentido: por un lado, la participación activa en la sociedad encuentra un referente en algunos de esos lugares comunes, pero por otro se desideologiza el protagonismo femenino en el ámbito público y se focaliza en algunas destacadas dirigentes.

En la Transición, la inclusión de la igualdad legal entre hombres y mujeres y el sufragio femenino en la Constitución de 1978 no provocó debate alguno,

89. Vid. JULIÁN, Inmaculada, «La representación gráfica de las mujeres (1936-1938)» y SERVÁN CORCHERO, Josefina y TRINIDAD MUÑOZ, Antonio, «Las mujeres en la cartelística de la guerra civil», ambos en Las mujeres y la Guerra Civil española, op. cit., pp. 353-358 y 364-370 respectivamente.

90. Vid. LEDESMA, José Luis, «Las mujeres en la represión republicana: apuntes sobre un 'ángulo muerto' de la guerra civil española», en NASH, Mary y TAVERA, Susana (eds.), Las mujeres y las guerras. El papel de las mujeres en las guerras de la Edad Antigua a la Contemporánea, Barcelona, 2003, pp. 441-458.

91. Pérez GARZÓN, Juan Sisinio, op. cit., p. 123. 
por los cambios sociales que había experimentado el país y el desarrollo del feminismo. Según Víctor Pérez Díaz, en la transición se inventó una nueva identidad de España democrática, contrapuesta a la franquista ${ }^{92}$; esta identidad democrática no se entendía ya sin la participación de las mujeres. El referente de 1931 estuvo presente en las declaraciones de igualdad, aunque la controversia que había suscitado fue olvidándose. Si bien no se cuestionaron los derechos políticos femeninos, sin embargo pervivió la discriminación de las mujeres en la política. En las listas electorales de 1977, las mujeres representaban el 13\% de las candidaturas, porcentaje que en 1979 se redujo a un 9,7\% y en 1982 se limitó a un 10,9\%; además la mayoría no ocupaba puestos de salida, por lo que sólo hubo un $6 \%$ de diputadas en 1977 , un $5,4 \%$ en 1979 y un $4,9 \%$ en $1982^{93}$. Esta exclusión de los espacios de poder en los partidos y las instituciones favoreció un debate muy interesante en el pujante movimiento feminista del momento, en torno a la intervención en el sistema político, entre las partidarias de la doble militancia - política y feminista, que creían posible cambiar desde dentro el funcionamiento de los partidos- $y$ aquellas que se decantaban por la militancia única feminista, decepcionadas ante la impermeabilidad de las agrupaciones políticas a la participación de las mujeres en igualdad de condiciones con los varones $^{94}$. Pero la percepción social era que la igualdad era plena.

En 2006 , en las conmemoraciones del $75^{\circ}$ aniversario de la proclamación de la República, se ha destacado como uno de los principales logros de la etapa republicana la aprobación del sufragio femenino, y la figura de Clara Campoamor ha sido muy difundida y homenajeada ${ }^{95}$. Esta circunstancia revela cómo la memoria de algunos aspectos relacionados con las mujeres contribuye a la consolidación simbólica de la democracia actual. Pero la mitificación de aquel hecho y de sus consecuencias contribuye a oscurecer las dificultades que, también hoy, encuentran las mujeres en su incorporación plena a la vida política. Es cierto que se han dado algunos pasos importantes en los últimos años, como la paridad en el gobierno socialista o las cuotas en las listas electorales, primero en los partidos de izquierda y después en todas las listas por aplicación de la Ley de Igualdad, que han permitido, por ejemplo, que el $39 \%$ de los concejales sean mujeres. Pero son medidas cuestionadas por algunas agrupaciones políticas conservadoras y parte de la opinión pública. Por otro lado, subsisten

92. PÉREZ DíAz, Víctor, La primacía de la sociedad civil, Madrid, 1993, p. 36.

93. SÁnCHEZ Hernández, María F., Liderazgo político de mujeres. Desde la Transición hacia las Cuotas. Estudio documental, Sevilla, 2003, pp. 55-92.

94. Vid., entre otros, AUGUSTÍN PUERTA, Mercedes, Feminismo: identidad personal y lucha colectiva (Análisis del movimiento feminista español en los años 1975 a 1985), Granada, 2003, pp. 161-176.

95. Coincidiendo con el aniversario, se han reeditado CAMPOAMOR, Clara, El voto femenino y yo, Barcelona, 2006 y FAGOAGA, Concha y SAAVEDRA, Paloma, Clara Campoamor, la sufragista española, Madrid, 2006 y 2007. También ha aparecido OfFen, Karen, Historia de una conquista. Clara Campoamor y el voto femenino, Madrid, 2007. Por otro lado, numerosas organizaciones de mujeres actuales han adoptado el nombre de Clara Campoamor y en menor medida de otras como Victoria Kent, lo cual refleja que estas figuras están muy presentes en la memoria colectiva del feminismo actual. 
elementos destacados que dificultan la actividad política femenina plena. Recientes estudios demuestran que en el ámbito municipal perviven diferencias en el acceso al poder -sólo hay un 15\% de alcaldesas-y un reparto sexuado de las responsabilidades -las mujeres son mayoritarias en las concejalías sociales y los varones en urbanismo y hacienda ${ }^{96}$. En el Congreso, la presencia de diputadas empieza a ser destacada, con 127 diputadas en la actualidad -un 36\% del total-, pero su permanencia en los escaños es muy inferior a la masculina, lo cual impide la consolidación de su carrera política ${ }^{97}$. Como indica Amelia Valcárcel, las mujeres "tenemos nominalmente derechos y de hecho carecemos de canales para ejercer bastantes de ellos ${ }^{98}$. En consecuencia, desde el feminismo se demanda una "democracia paritaria», que garantice la presencia de mujeres en centros de poder. No sólo con propuestas técnicas -cuotas, por ejemplo- sino políticas, y con «el conocimiento histórico y causal» de la exclusión política de las mujeres ${ }^{99}$.

Por otro lado, el concepto de ciudadanía ha dejado de tener un contenido exclusivamente político e incorpora otros elementos fundamentales en la vida de las mujeres. En este sentido, el recuerdo estereotipado de diversos aspectos relacionados con las mujeres de los años treinta también ha contribuido a una extensión de una ciudadanía social y civil femenina. En la Transición, bajo el lema "Lo personal es político», el movimiento feminista recordó algunas de las conquistas de la República y la Guerra para reclamar la aprobación del divorcio o la despenalización del aborto. En 1977, se celebró una entrevista de un alto contenido simbólico entre representantes de la Associació Catalana de la Dona y el presidente de la Generalitat en el exilio, Tarradellas, quien apoyó públicamente dichas reivindicaciones ${ }^{100}$. Ambas demandas, conseguidas con algunas limitaciones en 1981 y 1985, han favorecido el cuestionamiento de la identidad femenina doméstica, que identificaba a la mujer con la esposa y la madre. No obstante, estas medidas, como la despenalización del adulterio o del uso de anticonceptivos y otras muchas, no pueden ocultar la continuidad de desigualdades en el ámbito privado, que aflora en su cara más dramática en la violencia de género.

\section{REFLEXIONES FINALES}

En un texto reciente, Mary Nash alude a Habermas y a su demanda de promover una memoria constitucional "como herramienta de profundización en la ciudadanía y la solidaridad cívica», para concluir que el conocimiento de

96. «El poder local, cosa de hombres», El País, 7-XI-2007.

97. "Los hombres están en política; las mujeres pasan por ella», El País, 5-XI-2007.

98. VALCÁRCEL, Amelia, La política de las mujeres, Madrid, 1997, p. 208.

99. Сово, Rosa, «Sexo, democracia y poder político», Feminismo/s, n 3 (2004), p. 20. Vid. también SAAVEDRA, Paloma (dir.), Hacia una democracia paritaria, Madrid, 1999 o Sevilla Merino, Julia, Mujeres y ciudadania: la democracia paritaria, Valencia, 2004.

100. NASH, Mary, Dones en transició. De la resistència política a la legitimitat feminista: les dones en la Barcelona de la Transició, Barcelona, 2007, pp. 187-190. 
trayectorias históricas femeninas facilita la formación de la sociedad en valores de solidaridad y democracia ${ }^{101}$. En el mismo sentido, Pérez Garzón sostiene que "la historia, como constructora de memoria, es indispensable para la democracia»102. Por ello nos ha interesado señalar las aportaciones de la historia de género que pueden paliar las carencias de la visión mitificada de las mujeres en la memoria de la República y la Guerra, y por tanto contribuir a un mejor conocimiento del pasado y del presente. Pero además se ha prestado especial interés a las visiones actuales que se proyectan sobre el pasado, que a su vez, en un movimiento circular, son visiones del pasado que refuerzan algunas desigualdades en el presente. En este sentido, los mitos y estereotipos sobre las experiencias femeninas de los años treinta contribuyen a la consolidación de la democracia, por la inclusión de las mujeres en la ciudadanía, pero también a la despolitización, la confusión y la uniformización de la sociedad, y por tanto al debilitamiento del funcionamiento democrático a medio plazo.

El conocimiento riguroso de las vivencias y actitudes de las mujeres de esa época debe incluir no sólo la pluralidad de experiencias que van más allá de la víctima y la heroína, sino también los cambios y las permanencias en las relaciones de género, las luces y sombras de estos periodos. Debe insistir también en que los avances en la vida de las mujeres no fueron producto del simple paso del tiempo, sino del esfuerzo de muchas mujeres y de la voluntad política de algunos gobiernos. Sin ese esfuerzo y esa voluntad para incluir a las mujeres en los ámbitos públicos y privados en condiciones de igualdad con los hombres, tampoco progresará la sociedad actual hacia una profundización de la democracia. 